Asian J. Med. Biol. Res. 2015, 1 (1), 80-88

\author{
Asian Journal of \\ Medical and Biological Research \\ ISSN 2411-4472 \\ www.ebupress.com/journal/ajmbr
}

\title{
Article \\ Effects of feeding Bacillus subtilis to heat stressed broiler chickens with or without an antibiotic growth promoter
}

\author{
Bibek Chandra Roy ${ }^{1 *}$, Sachchidananda Das Chowdhury ${ }^{1}$ and S. M. Lutful Kabir ${ }^{2}$ \\ ${ }^{1}$ Department of Poultry Science, Bangladesh Agricultural University, Mymensingh-2202, Bangladesh \\ ${ }^{2}$ Department of Microbiology and Hygiene, Bangladesh Agricultural University, Mymensingh-2202, \\ Bangladesh
}

*Corresponding author: Bibek Chandra Roy, Department of Poultry Science, Bangladesh Agricultural University, Mymensingh- 2202, Bangladesh. E-mail: bibekdls@yahoo.com

Received: 18 May 2015/Accepted: 10 June 2015/ Published: 30 June 2015

\begin{abstract}
The effects of feeding probiotic (PB) with or without Lincomycin 2.2\% (AGP) were investigated in broiler chickens during summer. Seven hundred Cobb-500 one day old straight run broiler chicks were randomly distributed into four dietary treatments each of five replications. Four diets were compared: control; control diet plus PB (Bacillus subtilis DSM17299) at a level of $50 \mathrm{~g} / 100 \mathrm{~kg}$; control plus (AGP) at a level of $15 \mathrm{~g} / 100 \mathrm{~kg}$ and control plus a combination of PB and AGP $(50 \mathrm{gm} / 100 \mathrm{~kg}$ and $15 \mathrm{~g} / 100 \mathrm{~kg}$ respectively). Control birds were fed on a corn-soybean based starter mash that contained ME $3000 \mathrm{kcal} / \mathrm{kg}$ and CP 24.39\% from 0-21 days of age and a corn-soybean based grower mash of ME $3100 \mathrm{kcal} / \mathrm{kg}$ and CP 20.43\% during 22-35 days of age. The records were kept of feed intake (FI), body weight and mortality while weight gain, feed conversion ratio (FCR) and survivability were calculated. Temperature and humidity were recorded four times daily except during extreme heat stress when measurements were made more frequently. One bird that was close to average of pen weight was taken from each replication at the end of the trial and the birds were sacrificed to determine carcass characteristics. Both performance and carcass yield data were statistically analyzed. Birds that received $\mathrm{PB}$ and a combination of $\mathrm{PB}+\mathrm{AGP}$ treatments showed significant differences $(\mathrm{P}<0.01)$ from control with respect to body weight gain and FCR while feeding AGP alone although showed a decrease in feed intake. Abdominal fat was significantly $(\mathrm{P}<0.01)$ reduced in $\mathrm{PB}$ treated birds. Higher mortality was encountered in control group. Both PB alone and a combination of AGP treatments were able to show improved performance and reduced mortality, feeding PB alone may be practiced on the combined grounds of improved performance, efficiency in combating heat stress and to discourage the use of AGP in broiler diet.
\end{abstract}

Keywords: heat stress; probiotic; AGP; broiler chicken; performance; carcass traits

\section{Introduction}

The wide fluctuating temperatures, high humidity, excessive heat, heavy rainfall, drought are the consequences of climate change that affect poultry production negatively, particularly in open-sided houses. High ambient temperature is an important issue challenging the poultry industry in many countries which can exert deleterious effects on productive performances in broiler chickens (Cooper and Washburn, 1998).In broiler chickens, heat stress reduces feed consumption and weight gain (Farooqi et al., 2005). The onslaught of high temperature brings heat intolerance resulting in high stress, increased vulnerability to diseases, vaccine failures and disease outbreaks, poor FCR, reduction in body weight and even mortality. In addition, birds also start panting to bring down body temperature, which in turn leads to electrolyte imbalance. Consequently, production and performance goes down from the desired levels. So, high temperature during summer has a 
negative impact on birds' economic gain. There are two aspects to efficient summer stress management in poultry farming - good management practices and effective nutritional solutions. Application of electrolytes, acidifiers, probiotics, amino acids, vitamin $\mathrm{A}, \mathrm{B}_{2}, \mathrm{C}, \mathrm{D}, \mathrm{E}, \mathrm{K}$, cholin, biotin, chromium and betaine have been reported to be helpful in mitigating heat stress.

In mid 1940s, the use of antibiotics became a common practice in broiler production. There is increasing public health concern, over the use of antibiotic for growth promotion in food animal production that relates to the contribution of this use to increasing rates of antibiotic resistance. The European Union, in 1999, banned the use of most antibiotics for growth promotion to preserve the effectiveness of important human drugs (Casewell et al., 2003).In Bangladesh, there is a growing concern not to use antibiotic growth promoter in poultry diets unnecessarily, rather to find out alternatives to commonly used antibiotic to act as performance enhancer as well as for the improvement of gut health. Currently, probiotics have been used as a feed supplement in diets of different classes of poultry to enhance productive performance and immune responses. Probiotics supplementation to broiler diets had positive effects on body weight gain, feed conversion ratio, and mortality rate in broiler chickens (Anjum et al., 2005). Probiotics can also benefit the host animal by enhancing the synthesis of certain vitamins, providing digestive enzymes and increasing the production of volatile fatty acids that are finally metabolized in favour of the host (Fritts et al., 2000). Since, stress mitigating products are always costly, so any additional usages to minimize heat stress must be justified over the cost of production. In this study, an attempt has been made to explore the beneficial effects of Bacillus subtilies strain containing probiotic on heat stressed commercial broiler chickens given diets with or without an antibiotic growth promoter. Bacillus subtilis is a number of the mucosa associated bacterial population in the caeca of the chicken (Gong et al., 2002). The specific objectives of this experiment were: 1) to investigate the effects of Bacillus subtilis containing $\mathrm{PB}$ on heat stressed commercial broilers when supplemented alone or in combination with AGP; 2) to determine the carcass characteristics of finished broilers receiving different treatments and 3) to determine the cost-effectiveness of the application of PB and AGP in broiler production.

\section{Materials and methods}

The experiment was conducted in the experimental shed of an open sided house at Bangladesh Agricultural University (BAU) Poultry Farm, Mymensingh. Seven hundred Cobb- 500 one day old straight run broiler chicks were considered for the research. The duration of the trial was 35 days. Before the arrival of the experimental birds, the house was properly cleaned, washed, disinfected and dried. Twenty pens of equal sizes were made by wire-net and bamboo materials. The floor space allowed for each bird 1 sq.ft to ensure comfort of the birds. Feeders, waterers, buckets and all other necessary equipments were properly cleaned, washed and disinfected thoroughly with a disinfectant $\mathrm{TH}_{4}{ }^{+}$solution (Manufactured by-Sogeval, France, Marketed byCentury Agro Ltd, Bangladesh). Fresh and dry rice husks were used as litter materials at a depth of about $4 \mathrm{~cm}$. After 21days, old litter was replaced by fresh rice husk. The experimental broiler chicks were divided into four dietary groups and each group was replicated to five subgroups. First group of chicks was maintained on a control diet, the second group of chicks received an antibiotic growth promoter (AGP, $15 \mathrm{~g} / 100 \mathrm{~kg}$ feed, the third group of chicks was fed a probiotic (Bacillus subtilis strain, $50 \mathrm{~g} / 100 \mathrm{~kg}$ feed and the fourth group of chicks received both AGP $(15 \mathrm{~g} / 100 \mathrm{~kg})$ and probiotic $(50 \mathrm{~g} / 100 \mathrm{~kg})$.

Following arrival, they were placed randomly in the pens and their initial body weights were recorded. They were provided with glucovet powder (a mixture of $490 \mathrm{~g}$ glucose and $10 \mathrm{~g}$ vitamin $\mathrm{C}$ in $500 \mathrm{~g}$ powder, manufactured by the ACME Laboratories Ltd, Bangladesh) to overcome dehydration. The temperature and humidity was measured by an automatic digital thermo-hygrometer. Completely vegetable based diets were formulated by using locally available raw materials. Chemical analyses of experimental ration were done in Degussa Lab, Germany (Courtesy of Evonik Degussa $\mathrm{GmbH}$ ). Birds were supplied starter diet for the first 3 weeks (0-21days) and grower diet for the remaining two weeks (22-35days). Feeds and fresh clean drinking water were offered ad libitum. Strict bio-security program was maintained inside and outside of the experimental sheds as a most effective part of the disease prevention program.

The broiler chicks were weighed group-wise at the beginning of the experiment and then every seven days intervals until the termination of the experiment at 35 days of age. The birds were weighed in the evening between 6.30 and 7.00 PM. Nine chicks from each pen (26\%) were randomly weighed. The average live weight was recorded on weekly basis and at the end of the experiment. During the experimental period, usually, the temperature at chick level and that of the house were recorded four times (6 AM, 2 PM, 6 PM and 11 PM) in a day. The relative humidity was also recorded simultaneously by using an automatic thermo-hygrometer. At the 
end of the trial, the final body weight of the birds was recorded and average body weight was calculated. One broiler having near to pen average weight was sacrificed from each pen for recording meat yield parameters. Data of body weight, body weight gain, feed consumption, feed conversion ratio (FCR), livability and edible meat characteristics were subjected to analysis of variance (ANOVA) in a completely randomized design (CRD) employing SAS (2008) statistical computer package programme.

\section{Results}

\subsection{Live weight and live weight gain}

Table 1 indicates the productive performance of birds receiving diets containing probiotic with or without antibiotic growth promoter. The initial live weight of the birds of different dietary groups was approximately similar (47g). At the end of 35 days of age, both live weight and live weight gain were statistically similar in groups fed probiotic alone or in combination with AGP. This was followed by birds belonging to the control group and AGP group respectively and results of these two groups differed significantly from those of PB alone and $\mathrm{PB}+\mathrm{AGP}$ groups $(\mathrm{P}<0.01)$. Weekly body weight gains were more or less similar in all treatments up to two weeks of age but the effect of PB when fed independently or in combination with AGP became more apparent after two weeks of age (Figure 1). After fourth week, the body weight gain was more or less similar in probiotic+AGP and probiotic receiving groups but found significantly lower in both AGP and control groups.

Table 1. Effect of feeding probiotic (PB) and/or antibiotic growth promoter (AGP) on the growth performance of heat stressed broiler chickens (0-35 days).

\begin{tabular}{llllll}
\hline \multirow{2}{*}{ Variables } & \multicolumn{4}{c}{ Dietary treatments } & Statistical \\
\cline { 2 - 5 } & Control & Control+AGP & Control+PB & Con+AGP+PB & result \\
\hline Initial live weight $(\mathrm{g} / \mathrm{b})$ & $47.02^{\mathrm{a}} \pm 0.228$ & $47.04^{\mathrm{a}} \pm 0.466$ & $47^{\mathrm{a}} \pm 0.32$ & $47.02^{\mathrm{a}} \pm 0.822$ & $\mathrm{NS}$ \\
Final live weight $(\mathrm{g} / \mathrm{b})$ & $1897^{\mathrm{b}} \pm 23.26$ & $1819^{\mathrm{b}} \pm 55.64$ & $2014^{\mathrm{a}} \pm 13.94$ & $2027^{\mathrm{a}} \pm 13.98$ & $* *$ \\
Live weight gain $(\mathrm{g} / \mathrm{b})$ & $1850^{\mathrm{b}} \pm 36.46$ & $1772^{\mathrm{b}} \pm 55.64$ & $1967^{\mathrm{a}} \pm 13.94$ & $1980^{\mathrm{a}} \pm 13.98$ & $* *$ \\
Feed consumption $(\mathrm{g} / \mathrm{b})$ & $3349^{\mathrm{a}} \pm 37.58$ & $3288^{\mathrm{ab}} \pm 9.35$ & $3267^{\mathrm{b}} \pm 8.82$ & $3323^{\mathrm{ab}} \pm 23.64$ & $* *$ \\
FCR & $1.83^{\mathrm{a}} \pm 0.020$ & $1.86^{\mathrm{a}} \pm 0.050$ & $1.66^{\mathrm{b}} \pm 0.010$ & $1.67^{\mathrm{b}} \pm 0.01$ & $* *$ \\
Survivability $(\%)$ & $93.60^{\mathrm{b}} \pm 1.28$ & $98.20^{\mathrm{a}} \pm 1.20$ & $98.20^{\mathrm{a}} \pm 1.20$ & $97.60^{\mathrm{a}} \pm 1.12$ & $*$
\end{tabular}

$\mathrm{g} / \mathrm{b}=$ gram per bird, FCR= Feed Conversion Ratio, Means bearing uncommon superscripts differ significantly. *, $\mathrm{P}<0.05$; **, $\mathrm{P}<0.01$; NS, Non-significant

\subsection{Feed consumption and feed conversion ratio}

Table 1 shows that AGP, PB, PB + AGP supplemented groups consumed similar amounts of feed that were significantly lower than that of control group $(\mathrm{P}<0.01)$. Weekly feed consumption data revealed that birds of all groups consumed more or less similar amounts of feed up to 35 days of age but the control group had a trend of increased feed consumption after three weeks of age (Figure 2). This caused a sharp difference in cumulative feed consumption and therefore it differed statistically from other dietary groups.

Differences in cumulative feed conversion ratio (FCR) of the birds of different dietary groups differed significantly $(\mathrm{P}<0.01)$. The lowest value was obtained for birds supplemented with $\mathrm{PB}$. Both $\mathrm{PB}$ and $\mathrm{PB}+$ AGP supplemented groups showed similar efficiency (Figure 3).

\subsection{Livability}

The livability of AGP, $\mathrm{PB}, \mathrm{PB}+\mathrm{AGP}$ receiving groups was similar but comparatively higher mortality was found in the control group. The post-mortem examination revealed that the whole body was bluish in colour. The muscles were found dry and sticky, crop and gizzard were empty. Massive hemorrhage was found around the heart. The post-mortem lesions indicate that bird's mortality were the effects of heat stress. However, it was clear that the treated groups suffered significantly less from mortality than the control group $(\mathrm{P}<0.05)$. Figure 4 shows that the birds were mostly affected after three weeks and onward when extreme high temperature was recorded. 


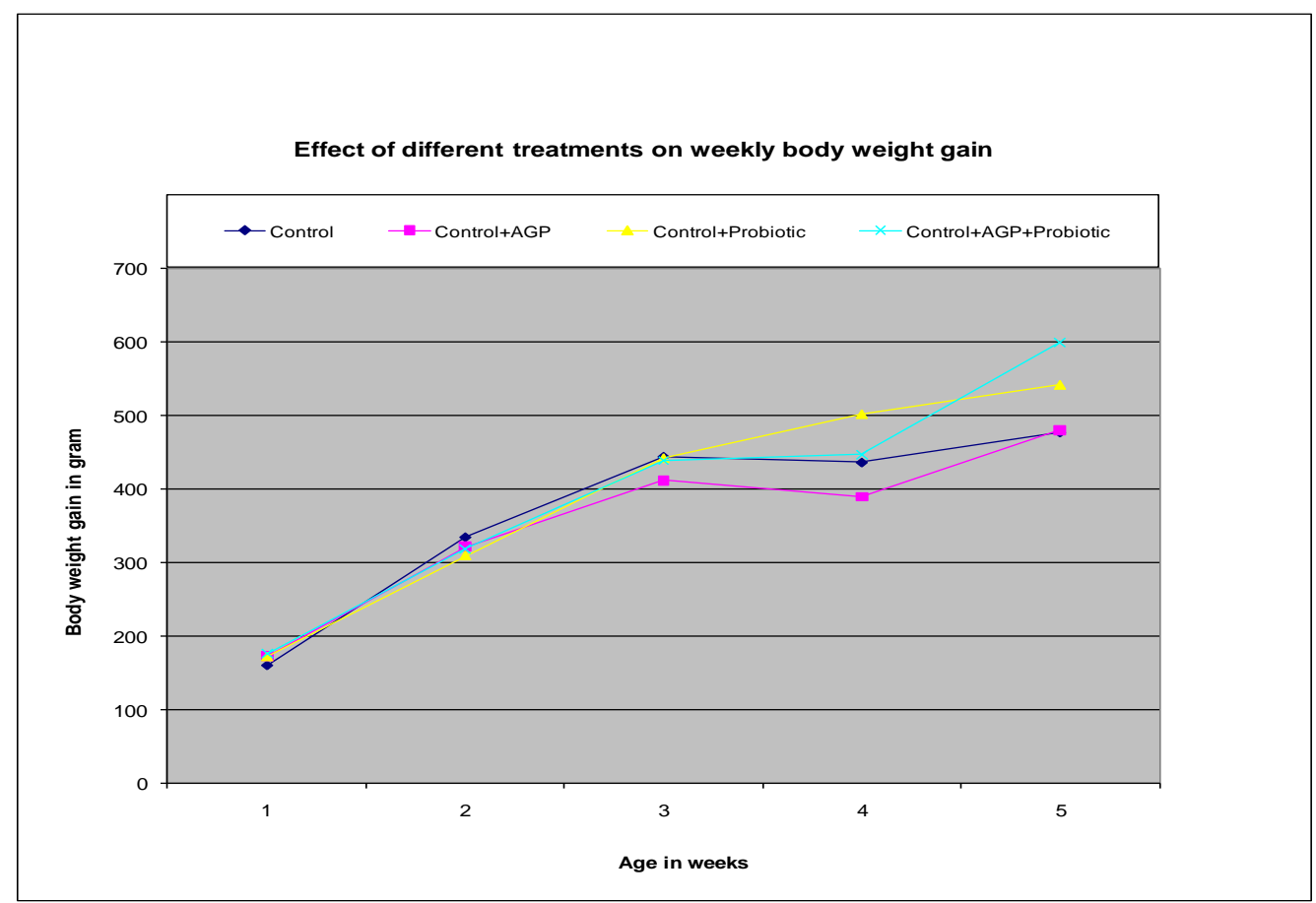

Figure 1. Effects of feeding probiotic (PB) and antibiotic growth promoter (AGP) either alone or in combination to heat stressed broiler chickens.

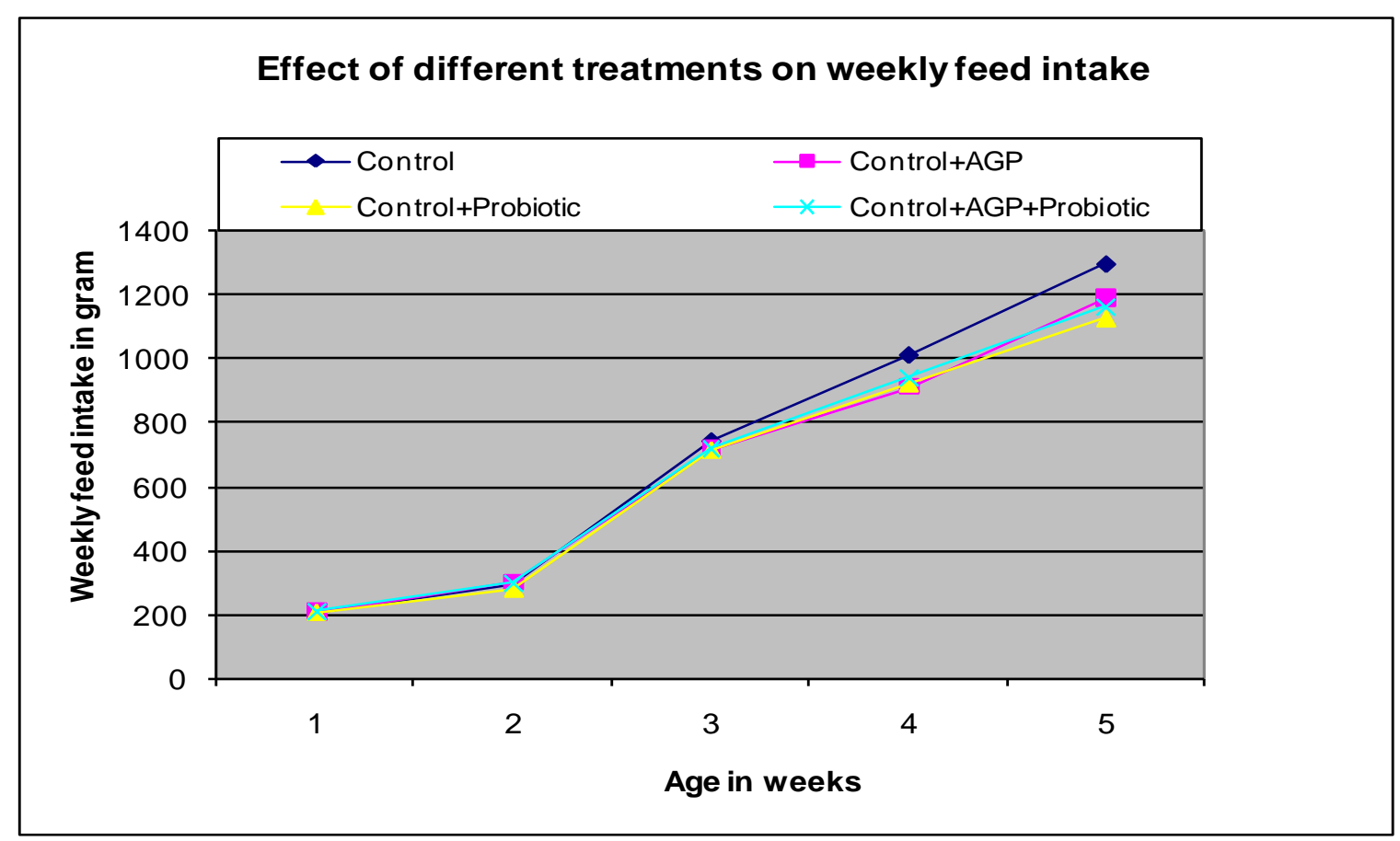

Figure 2. Feed consumption patterns of broiler chicks receiving probiotic (PB) and antibiotic growth promoter (AGP) either alone or in combination. 


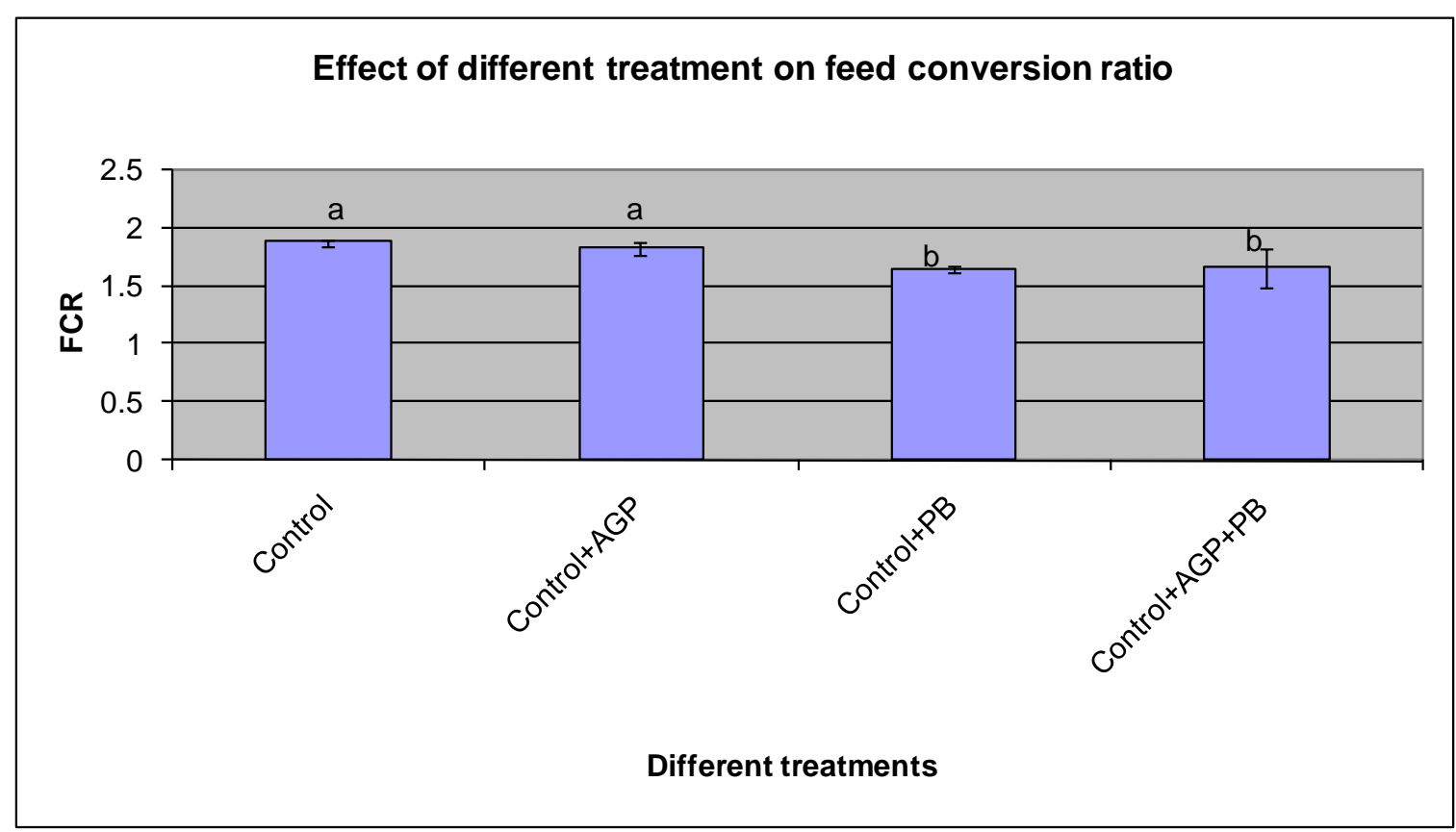

Figure 3. Feed conversion ratio (FCR) of broiler chicks receiving diets containing probiotic (PB) and antibiotic growth promoter (AGP) either alone or in combination.

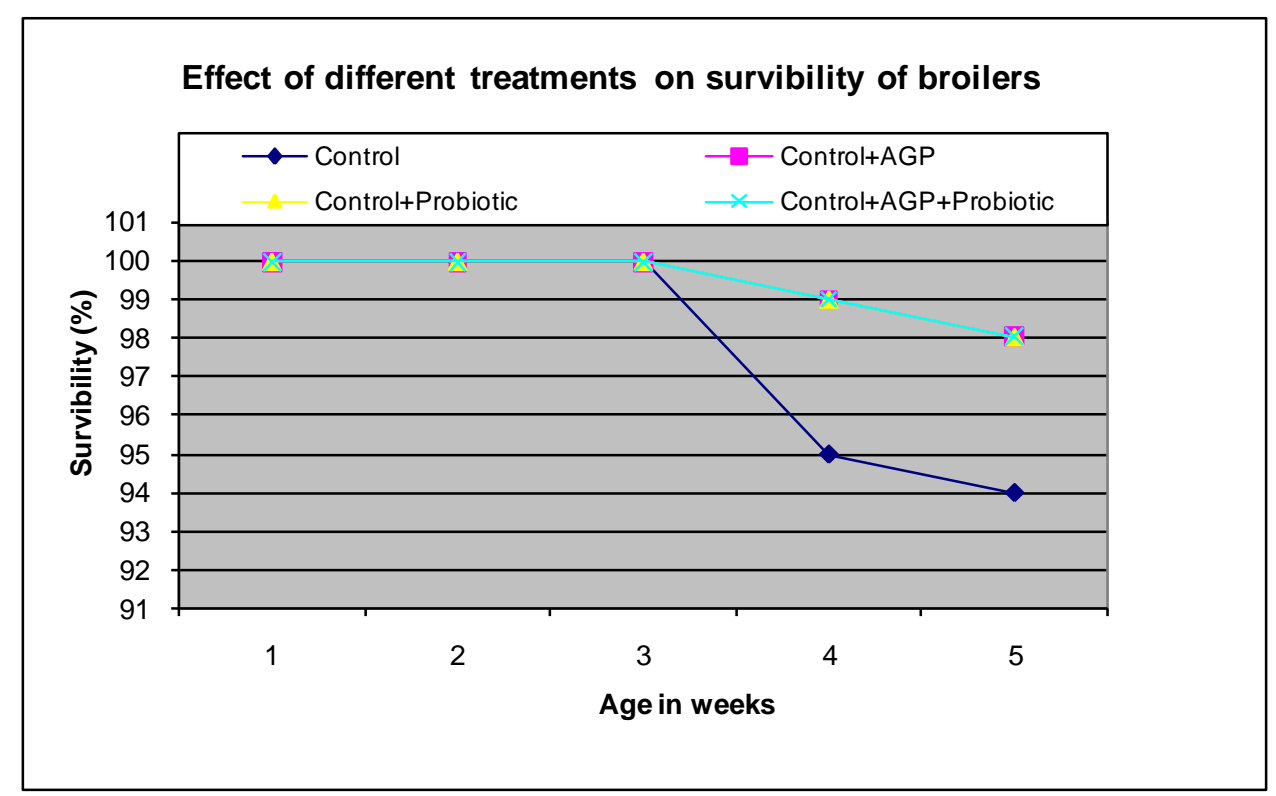

Figure 4. Survivability of heat stressed broiler chickens receiving diets containing probiotic (PB) and antibiotic growth promoter (AGP) either alone or in combination.

\subsection{Edible meat yield characteristics}

Some edible meat yield characteristics of broilers fed PB with or without AGP are shown in Table 2. Application of $\mathrm{PB}$ in the diet increased dressing yield, similar to $\mathrm{PB}+\mathrm{AGP}$ group $(\mathrm{P}<0.01)$. There was a tendency of increased thigh meat in both $\mathrm{PB}$ and $\mathrm{PB}+\mathrm{AGP}$ groups $(\mathrm{P}<0.01)$. Breast meat in $\mathrm{PB}$ group also numerically higher compared to the control. The liver weight was significantly lower in $\mathrm{PB}$ group. The abdominal fat significantly $(\mathrm{P}<0.01)$ reduced in both $\mathrm{PB}$ and $\mathrm{PB}+\mathrm{AGP}$ receiving groups. 
Table 2. Some edible meat yield characteristics of broilers fed on probiotic (PB) with or without antibiotic growth promoter (AGP) (0-35 days).

\begin{tabular}{llllll}
\hline Variables & Control & Control+AGP & Control+PB & Control +PB + AGP & $\begin{array}{l}\text { Statistical } \\
\text { result }\end{array}$ \\
\hline Dressing Percentage (\%) & $67.55^{\mathrm{b}} \pm 0.51$ & $69.95^{\mathrm{b}} \pm 0.46$ & $71.14^{\mathrm{a}} \pm 0.29$ & $70.68^{\mathrm{a}} \pm 0.63$ & $* *$ \\
Thigh (\%) & $8.97^{\mathrm{b}} \pm 0.28$ & $8.48^{\mathrm{b}} \pm 0.14$ & $10.16^{\mathrm{a}} \pm 0.27$ & $10.03^{\mathrm{a}} \pm 0.27$ & $* *$ \\
Drumstick (\%) & $6.09^{\mathrm{b}} \pm 0.12$ & $6.61^{\mathrm{a}} \pm 0.28$ & $6.30^{\mathrm{b}} \pm 0.09$ & $7.14^{\mathrm{a}} \pm 0.19$ & $* *$ \\
Breast meat (\%) & $28.99 \pm 0.33$ & $28.82 \pm 0.35$ & $29.96^{\mathrm{a}} \pm 0.76$ & $29.56 \pm 0.25$ & $\mathrm{NS}$ \\
Wing meat (\%) & $6.25^{\mathrm{a}} \pm 0.08$ & $5.80^{\mathrm{b}} \pm 0.09$ & $5.82^{\mathrm{b}} \pm 0.14$ & $6.53^{\mathrm{a}} \pm 0.12$ & $*$ \\
Liver (\%) & $3.61^{\mathrm{a}} \pm 0.09$ & $3.67^{\mathrm{a}} \pm 0.15$ & $2.95^{\mathrm{b}} \pm 0.05$ & $3.89^{\mathrm{a}} \pm 0.09$ & $*$ \\
Abdominal Fat (\%) & $2.76^{\mathrm{a}} \pm 0.19$ & $2.13^{\mathrm{b}} \pm 0.13$ & $1.03^{\mathrm{c}} \pm 0.11$ & $1.24^{\mathrm{c}} \pm 0.22$ & $* *$ \\
\hline
\end{tabular}

Means bearing uncommon superscripts differ significantly. *, $\mathrm{P}<0.05 ; * *, \mathrm{P}<0.01$; NS, Non-significant

\subsection{Cost-effectiveness of production}

The economics of feeding PB and AGP is shown in Table 3.The total production cost per bird was highest in control group followed by AGP+PB, AGP and PB group respectively. The total production cost per kg broiler was Tk. 127.32, Tk. 126.20, Tk. 114.79 and Tk. 112.14 for control, AGP, AGP+PB and PB group respectively. The profit both in terms of per bird and per kg broiler were higher in $\mathrm{PB}$ followed by AGP+PB, control and AGP group respectively. It is therefore clear that supplementation of $\mathrm{PB}$ and AGP+PB is profitable over control and AGP group. The additional costs incurred for probiotic over control were Tk. 0.91/bird and Tk. 0.95/kg live weight for PB+AGP group and Tk. 0.38/bird for AGP group. In contrast to this additional cost incurred for probiotic supplementation, the profit over control was Tk. 13/bird and Tk. 11/kg broiler in PB and $\mathrm{PB}+\mathrm{AGP}$ group respectively.

Table 3. Cost of production and profit in different probiotic (PB) and antibiotic growth promoter (AGP) groups of broilers.

\begin{tabular}{lllll}
\hline \multirow{2}{*}{ Variables } & \multicolumn{4}{c}{ Dietary treatments } \\
\cline { 2 - 5 } & Control & Control+AGP & Control+PB & Con+AGP+PB \\
\hline Feed intake (kg/chick) & 3.564 & 3.331 & 3.260 & 3.388 \\
Final weight (kg/b) & 1.897 & 1.819 & 2.014 & 2.027 \\
Feed price, 41.55 per kg & 148.00 & 138.00 & 135.00 & 141.00 \\
$\begin{array}{l}\text { AGP, 760/-per kg } \\
\text { PB, 560/-per kg }\end{array}$ & - & 0.38 & - & 0.38 \\
$\begin{array}{l}\text { Others (Chicks, vaccines, } \\
\text { disinfectants, labour etc.) }\end{array}$ & 85.00 & - & 0.91 & 0.95 \\
Total cost production /broiler & 233.00 & 223.38 & 85.00 & 85.00 \\
Total cost of production Tk. /kg & 127.32 & 126.20 & 220.91 & 227.29 \\
Sale price T/broiler 150/-per kg & 284.55 & 272.85 & 112.14 & 114.79 \\
Profit Tk./broiler & 51.55 & 49.47 & 302.10 & 304.05 \\
Profit Tk./kg & 27 & 27 & 81.19 & 76.76 \\
Profit Tk. /kg(over control) & -- & 0 & 40 & 38 \\
\hline
\end{tabular}

\section{Discussion}

This study revealed that the use of B. subtilis supplementation diet in broiler chickens resulted significantly $(\mathrm{P}<0.01)$ better weight gain and feed efficiency. Bacillus subtilis DSM17299 is known to favor the growth of lactic acid-producing bacteria (Knarreborg et al., 2008) and may lower the intestinal pH. Acidification of the intestinal environment was found to inhibit the growth of detrimental bacteria (e.g., Salmonella; Van Immerseel et al., 2006), which corresponds to the result in the present study. The body weight gain of AGP group was significantly lower than other groups, which indicates that AGP used in this study (lincomycin 2.2\%) might not 
be effective for growth promotion during high ambient temperature. But it may show synergistic effect with PB. Fritts et al. (2000) used the probiotic product containing Bacillus subtilis C-3102 in order to improve the performance and stabilize microflora in the digestive tract of broilers. When this product was administered to chickens in the diet for a period of 42 days, their live weight increased and feed conversion improved. Sabatkova et al. (2008) compared the efficacy of the probiotic BioPlus 2B with that of the Avilamycin (AGP) on performance indicators and slaughter yields in broiler chickens. The probiotic BioPlus 2B contains Bacillus licheniformis- $\mathrm{CH} 200$ and Bacillus subtilis-CH 201 are characterized by a high production of proteases, lipases and amylase in the small intestine. They also accelerate the metabolism and increase nutrient utilization. At the same time they also produces volatile fatty acids that decreases the $\mathrm{pH}$ of digestive tract, enhance the development of lactacidogenic microflora and reduce the number of pathogenic E.coli. But none of these studies were carried out during heat stress. However, highly significant $(\mathrm{P}<0.01)$ improvement in the BWG, FC, FCR were found in PB involved feed. This findings support the findings of other researchers (Lund et al., 2005; Knarreborg et al., 2008) who found better growth performance with B. subtilis DSM17299 in broiler chickens. The effect of feeding broilers with a $B$. subtilis supplemented diet included significantly higher body weights than that of control group. Likewise the favourable effect of $B$. subtilis supplemented feed was expressed throughout the growing period in this study. This result is consistent with the findings of Chiang and Hsieh (1995). In contrast, Yeo and Kim (1997) reported that the daily body weight gain of broiler chicks was increased only in the brooding phase of life, whereas the remaining period of life there was no difference in body weight gain. Regarding the better feed efficiency, Jin et al. (1996) obtained similar results to those reported here using B. subtilis in the feed of chickens. Chen et al. (2009) and Mutus et al. (2006) found that weight gain, feed consumption and feed conversion were not improved with addition of B. subtilis when it was combined with other probiotics in broilers. The broilers in the groups having B. subtilis supplemented feed had relatively higher carcass compared with chickens in the control group. Awad et al. (2009) also found higher carcass yield in PB incorporated group. In contrast, other authors found no differences in carcass yield between birds that were fed probiotics (Moreira et al., 2001; Vargas Jr. et al., 2002). No significant difference was observed in breast meat among the groups in this trial, which is in agreement with the results published by Chiang and Hsieh (1995).

Concerning thigh yields, treatments receiving probiotic showed higher leg yield $(\mathrm{P}<0.01)$. Breast meat did not show any significant difference. The wing meat significantly $(\mathrm{P}<0.05)$ reduced in $\mathrm{PB}$ group as compared to control and $\mathrm{AB}+\mathrm{AGP}$ receiving groups $(\mathrm{P}<0.01)$. The absolute and relative weight of the liver was significantly lower in the group fed with the $B$. subtilis diets than in the control group. This outcome was corroborated with Molnar et al. (2011) who found lower lever weight in PB involved diet in broiler chickens. In contrast to these results, Awad et al. (2009) and Samli et al. (2007) did not find significant differences in liver weights between the control and the probiotic supplemented groups. It was also observed that probiotics decreased abdominal fat. This result may be attributed to the reducing effect of probiotics on fat deposition (Mohan et al., 1996; Jin et al., 1998).In contrast to this result Chiang and Hsieh (1995) observed no significant difference in the abdominal fat content among the groups when broiler chickens fed diets with B. subtilis. The livability of AGP, $\mathrm{PB}, \mathrm{PB}+\mathrm{AGP}$ receiving groups was similar but comparatively higher mortality was found in the control group. However, it was clear that the treated groups suffered significantly less than the control group $(\mathrm{P}<0.05)$.

During high environmental temperatures $\left(35-38.9^{\circ} \mathrm{C}\right)$, relative humidity of $70-72 \%$ was recorded. There was an increase in panting of birds. Only those birds which were near to the drinker consumed more water while others even were very reluctant to move to waterer for drinking. The birds had a tendency of reduced feed intake. Movement of birds was almost stopped during the time of extreme heat stress but they usually took feed during early morning or at late night. The birds spread their legs backward, throat was straight forward and they spread wings both sides over the litter. The litter temperature under the birds was about $47^{\circ} \mathrm{C}$. The birds created an unknown sound like growling. It was a panic scenario. It seemed that all birds will die within few minutes. No precautions were taken to alleviate the negative effect of heat stress. Therefore mortality from the control group was recorded most in such a situation. The whole body of the dead bird was bluish in colour. The post-mortem examination revealed that muscles were found dry and sticky, crop and gizzard were empty. Massive hemorrhage was found around the heart. Both external symptoms and the post-mortem lesions indicated that mortality was caused by heat stress. 


\section{Conclusions}

The application of PB alone in the diet of broiler chicken was found to exert its effects either similar to or better than PB + AGP in combination while better than AGP alone. It appears that PB may be a suitable alternative to AGP used in this study. It is, therefore, concluded that Bacillus subtilis containing PB may be considered as an alternative to AGP on the combined grounds of its performance-enhancing ability, efficiency in combating heat stress and cost-effectiveness.

\section{Acknowledgements}

The authors thank National Agricultural Technology Project (NATP) for financial support.

\section{Conflict of interest}

None to declare.

\section{References}

Anjum MI, AG Khan, A Azim and M Afzal, 2005. Effect of dietary supplementation of multi-strain probiotic on broiler growth performance. Pak. Vet. J., 25: 25-29.

Awad WA, K Ghareeb, S Abdel-Raheem and J Bohm, 2009. Effects of dietary inclusion of probiotic and symbiotic on growth performance, organ weights, and intestinal histomorphology of broiler chickens. Poult. Sci., 88: 49-55.

Casewell M, C Friis, E Marco, P Mcmullin and I Phillips, 2003. The European ban on growth-promoting antibiotics and emerging consequences for human and animal health. J. Antimicrobial. Chemother., 52:15961.

Chen KL, WL Kho, SH You, RH Yeh, SW Tang and CW Hsieh, 2009. Effects of Bacillus subtilis var. natto and Saccharomyces cerevisiae mixed fermented feed on the enhanced growth performance of broilers. Poult. Sci., 88: 309-315.

Chiang SH and WM Hsieh, 1995. Effect of direct-fed microorganisms on broiler growth performance and litter ammonia level. Asian Australas. J. Anim. Sci., 8: 159-162.

Cooper MA and KW Washburn, 1998. The relationship of body temperature to weight gain, feed consumption and feed utilization in broilers under heat stress. Poult. Sci., 77: 237-242.

Farooqi HAG, MS Kahn, MA Khan, M Rabbani, K Pervez and JA Khan, 2005. Evaluation of betaine and vitamin $\mathrm{C}$ in alleviation of heat stress in broilers. Int. J. Agr. Biol., 5: 744-746.

Fritts Ca, JH Kersey, Ma Motl, EC Kroger, F Yan, J SI, Q Jiang, MM Campos, AL Waldroup and PW Waldroup, 2000. Bacillus subtilis C-3102 (Calsporin) improves live performance and microbiological status of broiler chickens. J. Appl. Poult. Res., 9:149-155.

Fuller R, 2001. The chicken gut microflora and probiotic supplements. Poult. Sci., 38: 189-196.

Gong J, RJ Forster, H YU, JR Chambers, PM Sabour, R Wheatcroft and S Chen, 2002. Diversity and phylogenic analysis of bacteria in the mucosa of chicken ceca and comparison with bacteria in the cecal lumen. FEMS Microbiol. Lett., 208:1-7.

Jin LZ, YW HO, N Abdullah, and S Jalaludin, 1996. Influence of dried Bacillus subtilis and lactobacilli cultures on intestinal microflora and performance in broilers. Asian Australas. J. Anim. Sci., 9: 397-403.

Knarreborg A, E Brockmann, K Hoybye, I Knap, B Lund, N Milora and TD Leser, 2008. Bacillus subtilis (DSM17299) modulates the ileal microbial communities and improves growth performance in broilers. Int. J. Prebiotic Probiotic, 3:83-88.

Lund B, S Hansen and P Kurti, 2005. Efficacy of Gallipro-A microbial feed additive for broilers. Pages 25-29 in Proc. $15^{\text {th }}$ Eur. Symp. Poult. Nutr. World's Poultry Science Association, Budapest, Hungary.

Mohan B, R Kadirvel, A Natarajan and M Bhaskaran, 1996. Effect of probiotic supplementation on growth, nitrogen utilization and serum cholesterol in broilers. Br. Poult. Sci., 37:395-401.

Molnar AK, B Podmaniczky, P Ku“'rti ${ }_{1}$, I Tenk, R Gla'vits, GY Vira'́g and ZS Szabo, 2011. Effect of different concentrations of Bacillus subtilis on growth performance, carcass quality, gut microflora and immune response of broiler chickens. Br. Poult. Sci., 52: 658-65.

Moreira J, AA Mendes, EA Garcia, RG Garcia, ICL Almeida, JR JGC, 2001. Efeito do uso do probiótico sobre o desempenho erendimento de carcaça em frangos de corte. In:XXXVIII Reunião Anual da SBZ, 2001, Piracicaba. Anais. Piracicaba, pp. 852-854. 
Mutus R, N Kocabagli, M ALP, N Acar, M Eren and SS Gezen, 2006. Effect of dietary probiotic supplementation on tibial bone characteristics and strength in broilers. Poult. Sci., 85: 1621-1625.

Sabatkova J, I Kumprecht, P Zobac, P Suchy and B Cermak, 2008. The probiotic bioplus $2 \mathrm{~b}$ as an alternative to antibiotics in diets for broiler chickens. Acta Vet. Brno, 77:569-574.

Samli HE, N Senkoylu, F Koc, M Kanter and A Agma, 2007. Effects of Enterococcus faecium and dried whey on broiler performance, gut histomorphology and microbiota. Arch. Anim. Nutr., 61: 42-49.

SAS, 2000. SAS/STAT User's Guide, Version 8 Edition, Cary, NC, USA: SAS Inst. Inc.

Van Immerseel F, JB Russell, MD Flythe, I Gantois, L Timbermont, F Pasmans, F Haesebrouck and R Ducatelle, 2006. The use of organic acids to combat Salmonella in poultry: A mechanistic explanation of the efficacy. Avian Pathol., 35:182-188.

Vargas Jr JG, RS Toledo, LFT Albino, HS Rostango, JE Oliveira and DCO Carvalho, 2002. Características de carcaça de frango de corte, submetidos a rações contendo probióticos, prebióticos eantibióticos. In:XXXIX Reunião Anual da SBZ, 2002, Recife.

Yeo J and KI Kim, 1997. Effect of feeding diets containing an antibiotic, a probiotic or yucca extract on growth and intestinal urease activity in broiler chicks. Poult. Sci.,76: 381-385. 